\title{
Leakage Causes Analysis on a Boiler Enclosure Wall Superheater
}

\author{
Li Weiyong $^{1, ~ a}$, He Yaofang ${ }^{1, b}$, Guan Xin ${ }^{1, c}$, Meng Yanjun ${ }^{1, d}$ \\ ${ }^{1}$ Hebei College of Industry and Technology, Shijiazhuang, 050016, China \\ aemail:13933882838@139.com, bemail:13933069680@139.com, cemail:xinguan11@126.com, de \\ mail:13831121839@139.com
}

Keywords: Leakage, superheater, weld parameter

\begin{abstract}
The leakage reasons for a boiler enclosure wall superheater were discussed based on experimental results of macro fracture observation, chemical composition analysis, metallurgical microstructure examination, SEM and EDS analysis. It was presumed that weld flaw firstly formed due to large weld process parameters, then propagated under long period fatigue stress and developed to penetrated crack, leading to final leakage. It was suggested that boiler supervision and four-tube inspection should be enhanced.
\end{abstract}

\section{Introduction}

Boiler four-tube leakage happened frequently and was the main reason of forced outage in thermal generator unit leading to huge damage and economic loss[1-4]. In order to ensure the safe and economic operation of the power plant and avoid similar event happening, it is very significant to carry out cause analysis and provide proper measurements in time.

This paper focused on a leakage event of a boiler wall enclosure superheater. A series of experiments were conducted and the results were discussed in this paper. The conclusions and suggestions were provided for guidance to the boiler supervision.

\section{Experimental Observation and Analysis}

The leakage occurred at the supporting position of micro expanding anti-wear brick of a boiler low temperature superheater, bursting at the weld of the supporting plate. The material of the tube was 15CrMoG and dimension $\Phi 42 * 5 \mathrm{~mm}$.

The macro photograph at the leakage position of the failure tube was given in Fig.1.

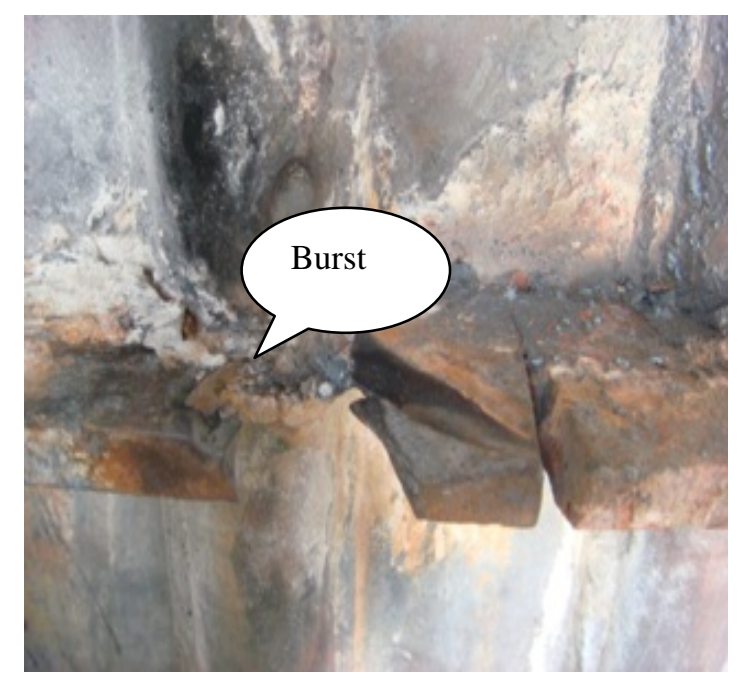

Fig.1 The macro photograph at the leakage position of the failure tube

Further observation on the tube leakage position was shown in Fig.2 and Fig.3. The leakage morphology suggested that there maybe existed weld defects such as pinhole, blowhole. 
The chemical composition of the failure wall enclosure tube was tested using ARL 3460 direct-reading spectrometer. The result was given in Table.1.

Table.1 The chemical composition result of the failure pipe sample

\begin{tabular}{cccccccc}
\hline Element & $\mathrm{C}$ & $\mathrm{Si}$ & $\mathrm{Mn}$ & $\mathrm{S}$ & $\mathrm{P}$ & $\mathrm{Cr}$ & $\mathrm{Mo}$ \\
\hline $\begin{array}{c}\text { Mass } \\
\text { percentage/wt } \\
\%\end{array}$ & 0.16 & 0.24 & 0.55 & 0.015 & 0.014 & 0.97 & 0.45 \\
\hline
\end{tabular}

According to the result in Table.1, the chemical composition of the failure tube meets the requirements of relative standard for $15 \mathrm{CrMoG}$.

The metallurgical microstructure of the wall enclosure tube was inspected and shown in Fig. 2.

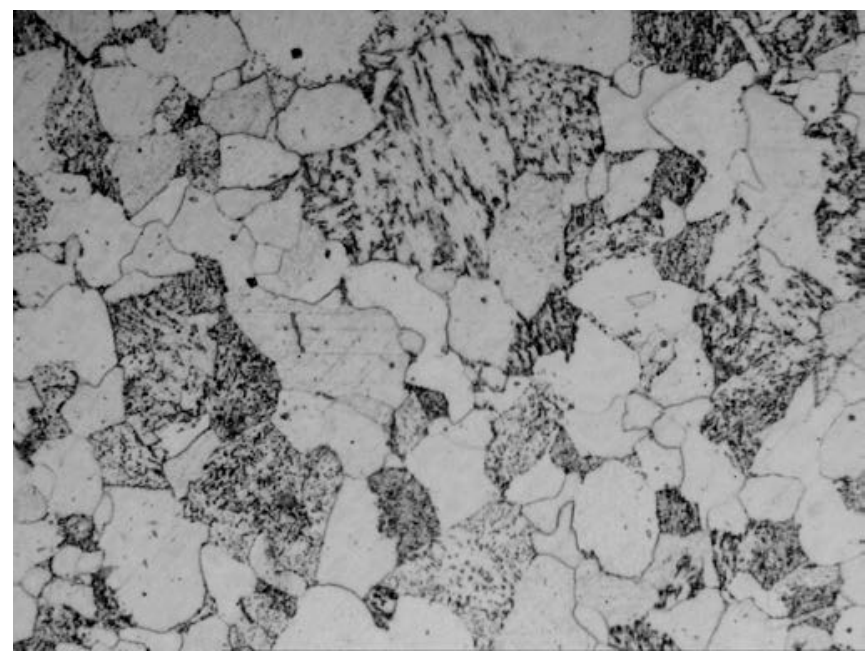

Fig.2 Metallurgical microstructure of the failure wall enclosure tube

From Fig.2 it was concluded that the tube exhibited microstructure of ferrite and pealite with degree 2.5 of nodulizing grade, meaning no abnormal phenomenon.

Samples were taken at the leakage position and surface morphology was observed by way of SEM. The SEM photo of the tube leakage position was illustrated in Fig.3. It was found there existed sign of drifting from inside to outside.

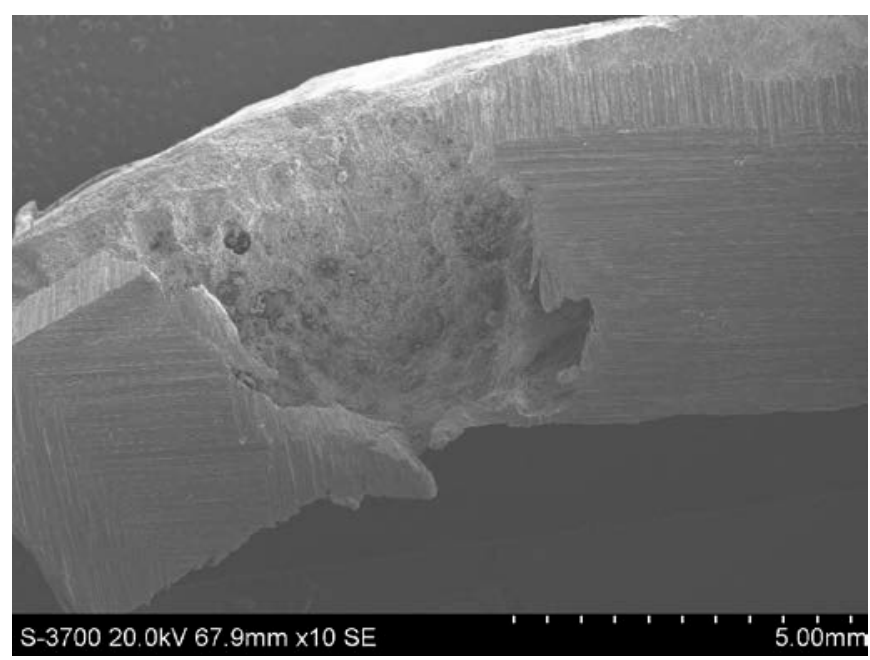

Fig.3 SEM morphology at the leakage position of the wall enclosure tube

The surface chemical composition was analyzed by EDS, the morphology of the examined area was shown in Fig.4. It could be seen that corrosion products covered the tube surface.

The EDS spectrum diagram and semi-quantity analysis of the examined surface were given in Fig. 5 indicating a quantity of sulfur about $0.72 \%$ existed in the leakage position. 


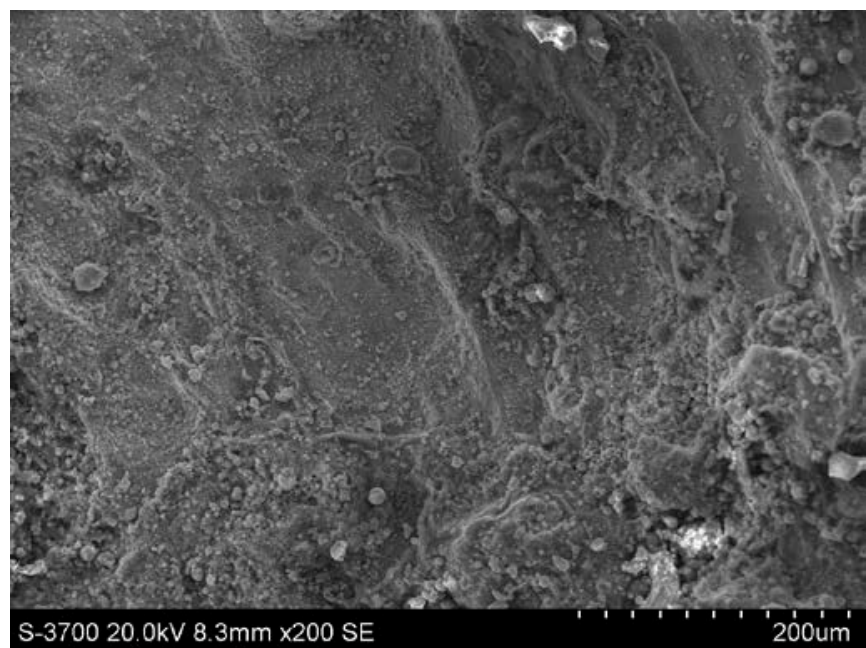

Fig.4 SEM morphology of examined surface of the failure tube

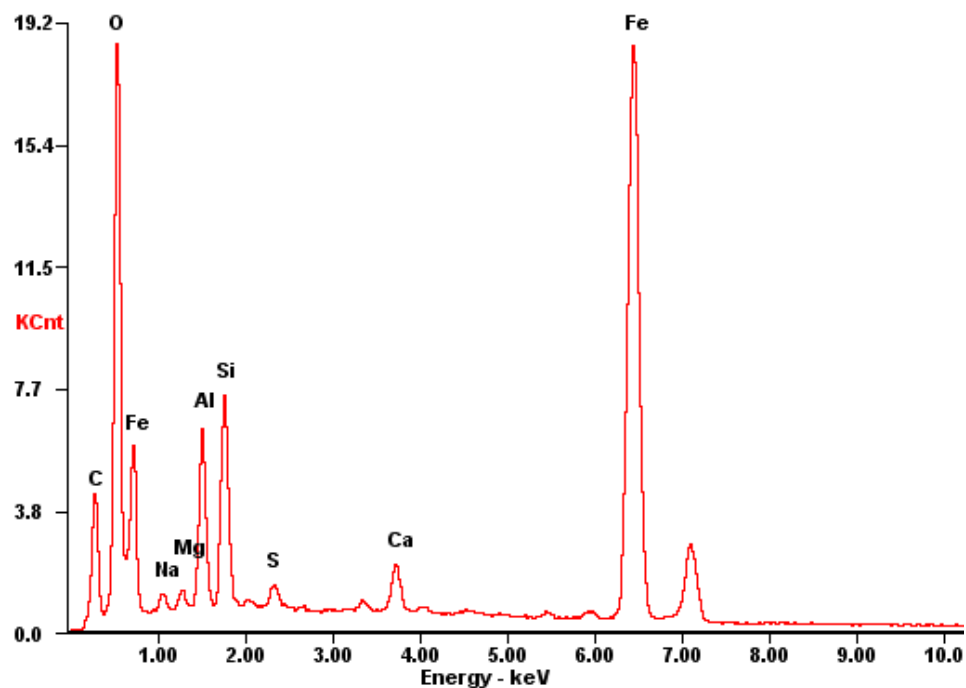

Fig.5 The EDS diagram of the examined tube surface

\section{Discussions}

Results of chemical composition of the enclosure wall tube met with the requirements of relative standard, and its metallurgical microstructure as ferrite and pealite with degree 3 nodulizing grade was normal. EDS indicated certain quantity of sulfur existing on the tube surface at its leakage position.

Based on macro observation result, the burst located at the weld of supporting brick plate, where was prone to form stress concentration due to temperature change for unit starting, stopping and load increasing or decreasing[5]. In addition, it was suggested that tube was hurt and induced weld defect because of overlarge welding process parameters. Under conditions of both weld defect and thermal stress, the defect propagated due to long time converted stress, became penetrating defect and finally led to tube leakage.

Although there was sulfur containing on the tube surface at the leakage position, its low quantity suggested that was because of sintering products deposition.

\section{Conclusions and Suggestions}

The leakage reasons of enclosure wall superheater were discussed based on experimental results. The leakage procedure was analyzed as follows: Firstly weld defect formed due to overlarge welding 
process parameters. Then the defect propagated under long time converted stress till formed penetrating defect, leading to final leakage of the tube.

Based on above conclusion, it was suggested that boiler supervision and leakage inspection for four types of tubes should be strengthened.

\section{References}

[1] A.K.Ray, Y.N.Tiwari. Engineering Failure Analysis, 2000, 7: 359-376

[2] Pavlovsky J, Million B, Ciha K, et al. Materials Science and Engineering, 1991, A149: 105-110. Yingting Dou, Jun Li, Zheng Zhang. Materials Engineering, 2012, (4): 12-16.

[3] Lundin C D, Khan K K, Yang D. WRC Buletin, 1995(407): 1.

[4] Davis C L, King J E. Metallurgical Transactions A, 1994, 25( 3) : 563-573.

[5] Jing jiangfeng, Zhang lei, Lu jun, et al. Cracking analysis of boiler water cooling wall tube, PTCA ( PartA. Phys.Test.) Vol. 47(7) (2011), p. 437-440. 